\title{
Review of the book Fundamentals of Power Electronics: Operating Principles, Design, Formulas, and Applications by Yuriy Rozanov, Sergey Ryvkin, Evgeny Chaplygin, and Pavel Voronin. CRC Press, 2015, hardcover, 489 pp. ISBN $9781482298796^{1}$
}

DOI: $10.3103 / \mathrm{S} 1068371215100144$

Today, in almost all the world's countries, power electronics is part of the range of research engaged in by universities and research centers working in the field of energy production and transmission. In my opinion, this book will find many readers, since it gives a clear picture of today's situation in the area of power electronics and the main paths of its development. It is a very good manual for engineers and researchers, in which they can find the basic features of power electronics and its advantages and disadvantages. It will be very useful for readers, because the design concepts of power electronics are presented from the point of view of control theory.

Power electronics is an integrated science that uses knowledge from various basic sciences. Using our knowledge of power electronics yields a synergetic effect only in the case in which all the advantages of all power electronics parts are used. The book gives a balanced and integrated presentation of power electronics and imparts readers with the basic knowledge needed for full use of the potential of power electronics.

The authors are qualified experts in the field. One of the authors, Prof. Sergey Ryvkin, was my PhD student and took the first steps in the field of sliding mode control. After obtaining his PhD, Prof. Ryvkin continued to work with me as a member of my laboratory in the field of sliding mode control for electrical drives. Professor Ryvkin is now a well-known researcher in our "sliding mode family." His findings allow engineers to design high-performance low-cost drives that are resistant to disturbances.

\footnotetext{
${ }^{1}$ The article was translated by the authors.
}

Prof. Yuriy Rozanov is a well-known Russian researcher and educator. He is an IEEE Fellow. He has published many textbooks on power electronics that are very popular for students in Russia. The teaching experience of Drs. E.E. Chaplygin and P.A. Voronin and their dozens of publications have let them make a significant contribution to the book with a clear explanation of the main operating modes of power converters.

The book brings together only important, more specialized knowledge that will help readers to understand the main principles of power electronics and, if needed, to develop practical solutions for the design and implementation of power electronics applications.

The interested reader can find notable information related to new areas of power electronics applications, such as renewable energy production, transmission, and distribution, especially options for control that increase the efficiency of power distribution and consumption.

During the last decade, power electronics has been developing rapidly, and this book combines traditional methods with new ones that require specialized knowledge, e.g., the sliding mode control, neural network, fuzzy system, and evolutionary methods. There is a collection of various applications of power electronics that can help readers to understand how to utilize the advantages of different modern methods.

This clear, integrated presentation that calls attention to the main features of power electronics may serve as a good tool in power electronics instruction.

Professor Vadim Utkin, Ohio State University, IEEE Fellow 